\title{
Light and Electron Microscopy Studies of the Visible Diffusion Zone of Mild Steel Pack Cyanided in Processed Cassava Leaves
}

\author{
Akinluwade Kunle Joseph ${ }^{1,2,3}$, Adelana Rasaki Adetunji ${ }^{1,4}$, Mosobalaje Adeoye ${ }^{4}$, Lasisi Ejibunu Umoru ${ }^{4}$, \\ Adeyinka Taofeek Taiwo ${ }^{1}$, Peter Kalu ${ }^{5}$, Azeez Rominiyi ${ }^{1,4}$, Dayo Adeyemi Isadare ${ }^{1,4}$ Winston Wole Soboyejo $^{2}$, \\ and Olusegun Oyeleke Adewoye ${ }^{2}$ \\ 1. Prototype Engineering Development Institute, National Agency for Science and Engineering Infrastructure (NASENI), Ilesa \\ 233036, Nigeria \\ 2. Department of Materials Science and Engineering, African University of Science and Technology, Abuja 900108, Nigeria \\ 3. Department of Chemical, Materials and Biomolecular Engineering, University of Connecticut, Farmington, CT 06032, USA \\ 4. Department of Materials Science and Engineering, Obafemi Awolowo University, Ile-Ife 220282, Nigeria \\ 5. Department of Mechanical Engineering, Florida Agricultural and Mechanical Engineering University, Florida 34420, USA
}

Received: June 23, 2013 / Accepted: July 19, 2013 / Published: September 25, 2013.

\begin{abstract}
This study investigates the microstructure of the visible diffusion zone formed in low carbon steel pack cyanided using processed cassava leaves. Standard parts machined from low carbon steel were pack cyanided by high temperature in-situ diffusion of nascent carbon and nitrogen into austenite. Formation of a visible diffusion zone was confirmed after observation with a Reichert-Jung Polyval optical microscope coupled with Zeiss AxioCam ICc 1 camera. High magnification Scanning Electron Microscope (SEM) imaging of the visible diffusion zone was done with a CamScan Series 2 scanning electron microscope. The zone was found variable in depth as measured from a representative position. The structure of all samples consists of ferrite and pearlite as determined by optical and SEM examination. Resulting products were thus both tough and hard suitable for service environments requiring high resistance to both wear and impact failure.
\end{abstract}

Key words: Cassava leaves, visible diffusion zone, SEM, low carbon steel, ferrite, austenite.

\section{Introduction}

Product development and machine building are both central to industrialization. This explains why virtually all developed and growing economies of the world are involved in production of consumer goods and services [1]. Developed products, whether cast or machined, often require post fabrication heat treatment such as hardening to prevent rapid wear of contacting surfaces in service environment.

Corresponding author: Akinluwade Kunle Joseph, senior research \& development officer, research fields: surface treatment and advanced materials; advanced manufacturing techniques (AMT). Email: jakinluwade@yahoo.com.
There are two distinctly different approaches to the various methods for surface hardening: methods that involve an intentional build-up or addition of a new layer and methods that involve surface and subsurface modification without any intentional build-up or increase in part dimensions [2]. Pack cyaniding belongs to the second group.

The development of the pack cyaniding technique using cassava waste [1, 2], characterization of the cases formed and mathematical modelling of the cassava pack cyaniding process [3] have been reported. The presence of cyanogenic glucoside in cassava plant could be the accumulation of products of catabolism of 
amino acids [4] or a mechanism for deterring predators [5]. Cassava contains some amount of cyanide that is often removed as waste during processing [1]. Previous investigation into this cyanide toxicity [6-8] has been aimed at destroying the cyanide content in order to render cassava less harmful to the consuming populace.

Earlier work has investigated the industrial application of the cyanide content in cassava in the cyanidation of gold [9], and recently in pack cyaniding of low carbon steels. The present work seeks to investigate the microstructure of the visible diffusion zone of mild steel samples pack cyanided in processed cassava leaves using optical and scanning electron microscopes.

\section{Experiments}

Suitably dimensioned low carbon steel samples were pack cyanided at $950{ }^{\circ} \mathrm{C}$ in $125 \mu \mathrm{m}$ processed cassava leaves according to the pack cyaniding method developed by Adetunji and Akinluwade [1, 2]. The steel samples were treated at 3, 4, and $5 \mathrm{~h}$. Small sections of each sample were taken for mounting in compression mount epoxy media, and polished to a final stage of $0.04 \mu \mathrm{m}$ particle size colloidal silica. All samples for micro-examination were prepared in accordance with ASTM E3-01. A visible diffusion zone was identified with the aid of a Reichart-Jung Polyval optical microscope coupled Zeiss AxioCam ICc 1 digital camera, operating with Zeiss AxioVision V 4.7 imaging software. The case and core microstructure were captured on the light microscope at variable magnifications. Scanning electron microscopic imaging of the visible diffusion zone was conducted with a CamScan Series 2 scanning electron microscope. SEM images of the case and the core were obtained at a high magnification of $\times 3,000$.

\section{Results and Discussion}

The visible diffusion zones are a region of high carbon concentration owing to the diffusion of carbon from processed cassava powder into the steel at austenitizing temperature. Carbon diffusion is highly favoured at $950{ }^{\circ} \mathrm{C}$ partly because the solubility of carbon in austenite is high and partly because longer soaking time increases diffusion according to Fick's law.

$$
\begin{aligned}
& J=-D \frac{\partial c}{\partial x} \\
& x=\sqrt{2 D t}
\end{aligned}
$$

These zones are shown in Figs. 1-3 as dark topmost region.

The SEM images reported at Figs. 4-6 show formations of pearlite and ferrite phases for the visible diffusion zone (VDZ).

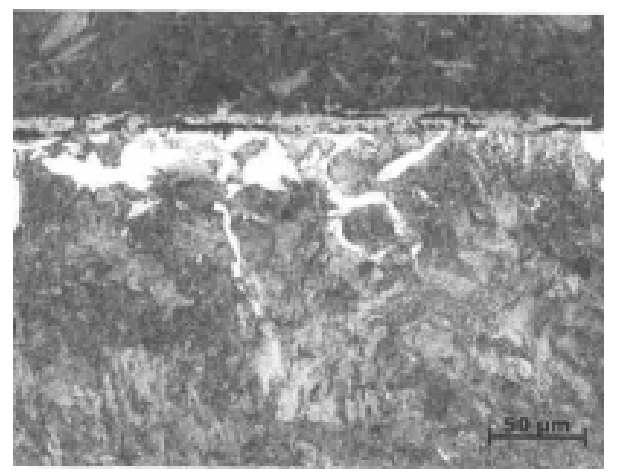

Fig. 1 Surface layer of sample treated for $5 \mathrm{~h}, \times 200$.

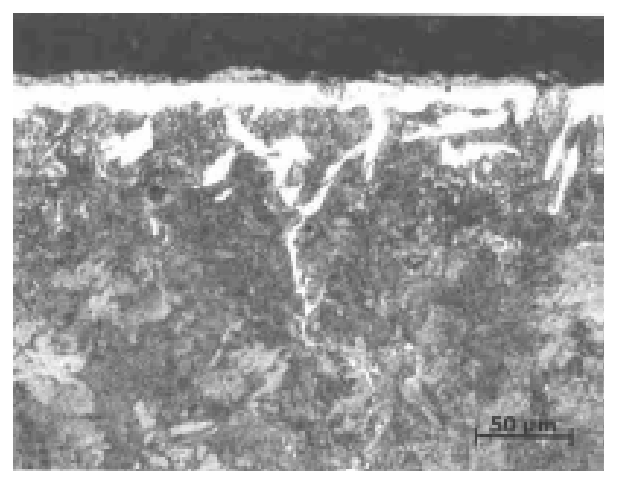

Fig. 2 Surface layer of sample treated for $4 \mathrm{~h}, \times 200$.

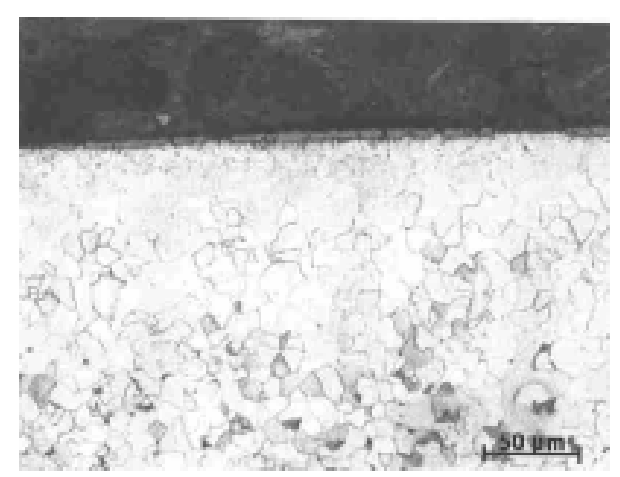

Fig. 3 Surface layer of sample treated for $3 \mathrm{~h}, \times 200$. 

Processed Cassava Leaves

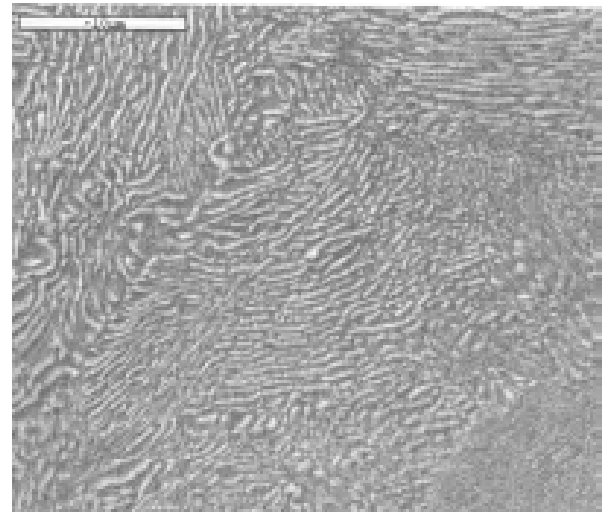

Fig. 4 Micrograph of VDZ at $5 \mathrm{~h}$ treatment $\times 3,000$.

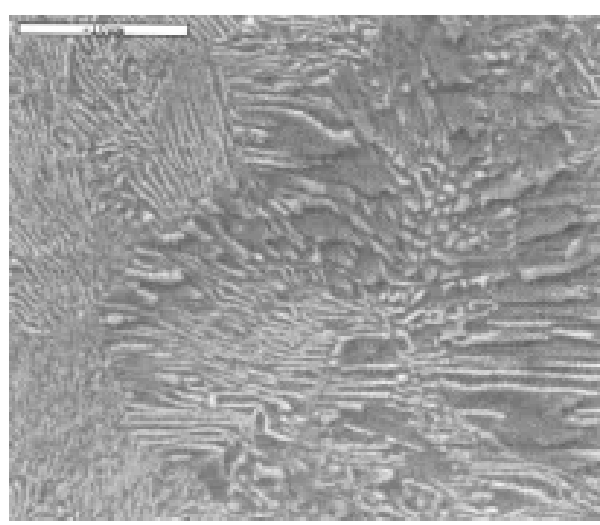

Fig. 5 Micrograph of VDZ at 4 treatment $\times 3,000$.

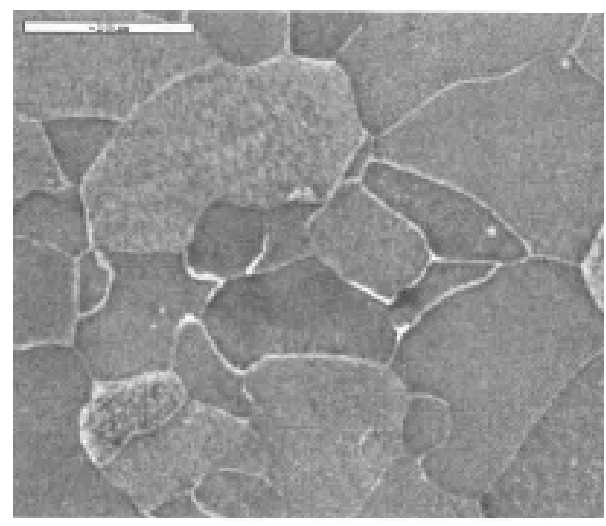

Fig. 6 Micrograph of $\mathrm{VDZ}$ at $3 \mathrm{~h}$ treatment $\times 3,000$.

The visible diffusion zone consists of predominant pearlite phase which provides hardness while the cores consist of predominant ferrite which provides ductility. Figs. 7-9 show the SEM of the cores.

Formation of predominant pearlite at the visible diffusion zone is made possible through the diffusion of atomic carbon into the steel surface in appreciable quantity. In application, hardness provides wear resistance against abrasion while ductility provides

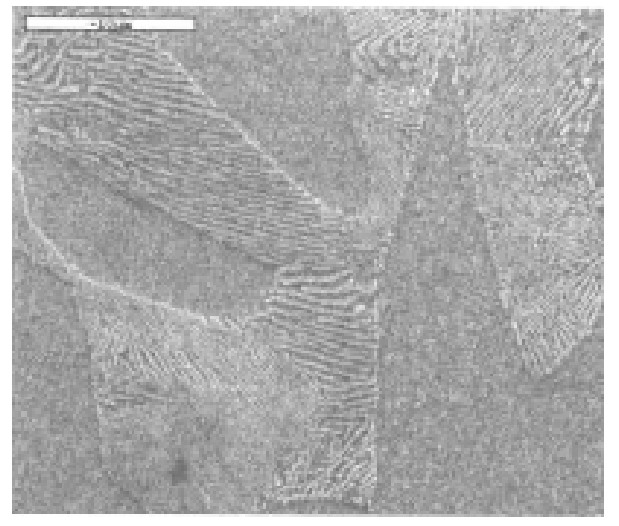

Fig. 7 Core micrograph of VDZ at $5 \mathrm{~h}$ treatment $\times 3,000$.

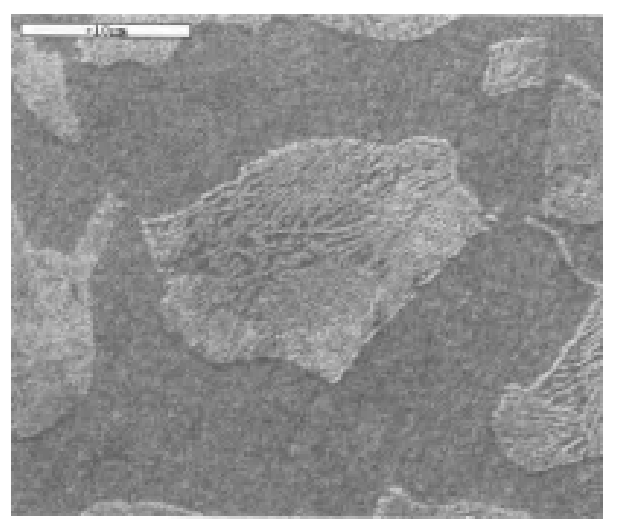

Fig. 8 Core micrograph of VDZ at $4 \mathrm{~h}$ treatment $\times 3,000$.

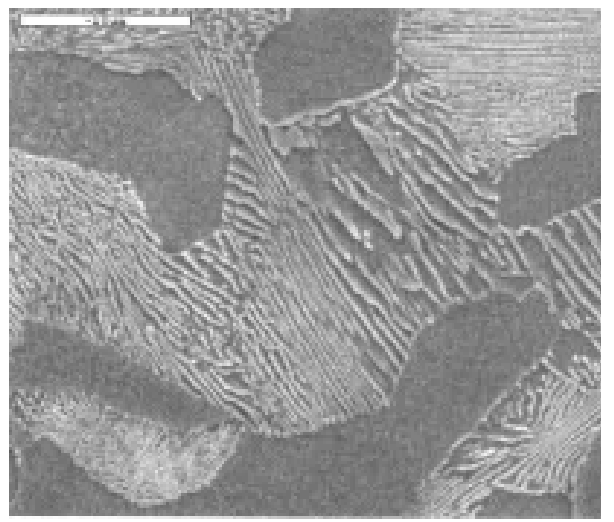

Fig. 9 Core micrograph of VDZ at $3 \mathrm{~h}$ treatment $\times 3,000$.

toughness against failure due to impact or torsional loading. Consequently, parts treated this way will show improved wear resistance and strength with a longer life in their service environment.

\section{Conclusions}

The following conclusions can be drawn from the results of this work.

(1) A region of visible diffusion zone was formed 

Processed Cassava Leaves

after mild steel was pack cyanided in processed cassava leaves at $950{ }^{\circ} \mathrm{C}$;

(2) The visible diffusion zone is a region of high carbon concentration owing to diffusion of carbon from processed cassava powder;

(3) SEM images taken showed that the microstructure of the cases consists of a predominant pearlite phase while the cores are composed of predominant ferrite;

(4) This method is capable of increasing the wear resistance of ferrous parts at the surface and torsional resistance at the core for a longer service life in application.

\section{Acknowledgments}

The authors wish to express their appreciation to the following institutions for their support during the developmental stages of this work.

(1) Raw Materials Research and Development Council, Abuja, Nigeria;

(2) National Agency for Science and Engineering Infrastructure, Abuja, Nigeria;

(3) Department of Mechanical Engineering, Florida Agricultural and Mechanical Engineering University (FAMU), USA.

\section{References}

[1] K.J. Akinluwade, A.R. Adetunji, M.O. Adeoye, L.E.
Umoru, P.N. Kalu, A.T. Taiwo, et al., Development of an environmentally friendly in-situ pack cyaniding technique, Journal of Minerals \& Materials Characterization \& Engineering 11 (1) (2012) 21-30.

[2] A.R. Adetunji, B.E. AttahDaniel, M.O. Adeoye, L.E. Umoru, C.E. Adeyinwo, D.A. Pelemo, et al., Metallographic studies of pack cyanided mild steel using cassava leaves, Materials and Manufacturing Processes 23 (4) (2008) 385-390.

[3] O.J. Ibironke, A. Falaiye, T.V. Ojumu, E.A. Odo, O.O. Adewoye, Case-depth studies of pack cyaniding of mild steel using cassava leaves, Materials and Manufacturing Processes 19 (5) (2004) 899-905.

[4] E.E. Conn, Cyanogenic Glucosides: Their occurrence, biosynthesis and function, chronic cassava toxicity, in: Conference Proceedings IDRC, Ottawa, Canada., 1973, pp. 55-63.

[5] W. Hosel, The Enzymatic Hydrolysis of Cyanogenic Glucosides, Cyanide in Biology, Academic Press, London. 1981, pp. 217-232.

[6] M.G. Bradbury, S.V. Egan, J.H. Bradbury, Picrate paper kits for determination of total cyanogens in cassava roots and all forms of cassava products, J. Sci. Food Agric. 79 (1999) 593-601.

[7] M.R. Haque, J.H. Bradbury, Preparation of linamarase solution from cassava latex for use in the cassava cyanide kit, Food Chemistry 67 (1999) 305-309.

[8] M.R. Haque, J.H. Bradbury, Total cyanide determination of plants and foods using picrate and acid hydrolysis methods. Food Chemistry 77 (2002) 107-114.

[9] A.R. Adetunji, Use of cyanide solution from cassava for the extraction of gold, M.Sc. Thesis, Obafemi Awolowo University, Ile-Ife, Nigeria, 1991. 